OPEN ACCESS

Edited by:

Joseph Firth,

Western Sydney University, Australia

Reviewed by:

Lee Smith

Anglia Ruskin University,

United Kingdom

Ahmed Jerome Romain

University of Montreal Hospital Centre

(CRCHUM), Canada

*Correspondence:

Alexandra Berry

alexandra.berry-2@

postgrad.manchester.ac.uk

Specialty section:

This article was submitted to

Schizophrenia,

a section of the journal

Frontiers in Psychiatry

Received: 09 October 2018 Accepted: 26 November 2018 Published: 12 December 2018

Citation:

Berry A, Drake RJ, Webb RT, Ashcroft DM, Carr MJ and Yung AR (2018) Investigating the Agreement Between Cardiovascular Disease Risk Calculators Among People Diagnosed With Schizophrenia.

Front. Psychiatry 9:685. doi: 10.3389/fpsyt.2018.00685

\section{Investigating the Agreement Between Cardiovascular Disease Risk Calculators Among People Diagnosed With Schizophrenia}

\author{
Alexandra Berry ${ }^{1 *}$, Richard J. Drake ${ }^{1,2}$, Roger T. Webb ${ }^{1}$, Darren M. Ashcroft ${ }^{3}$, \\ Matthew J. Carr ${ }^{1}$ and Alison R. Yung 1,2,4 \\ ${ }^{1}$ Division of Psychology \& Mental Health, School of Health Sciences, Faculty of Biology, Medicine and Health, Manchester \\ Academic Health Sciences Centre (MAHSC), University of Manchester, Manchester, United Kingdom, ${ }^{2}$ Greater Manchester \\ Mental Health NHS Foundation Trust, Manchester, United Kingdom, ${ }^{3}$ Division of Pharmacy \& Optometry, School of Health \\ Sciences, Faculty of Biology, Medicine and Health, Manchester Academic Health Sciences Centre (MAHSC), University of \\ Manchester, Manchester, United Kingdom, ${ }^{4}$ Orygen, The National Centre of Excellence in Youth Mental Health, The \\ University of Melbourne, Parkville, VIC, Australia
}

Background: People diagnosed with schizophrenia have a much reduced life expectancy compared to the general population, and a more than doubled risk of dying from cardiovascular disease (CVD). Existing CVD risk calculators can be used to detect people with an elevated predicted risk of CVD to inform interventions to reduce risk.

Aims: This study aimed to compare four different risk calculators for 10-year predicted CVD risk in a sample of people with schizophrenia.

Methods: Thirty participants with a diagnosis of schizophrenia spectrum disorders living within Greater Manchester, United Kingdom took part. Ten-year predicted cardiovascular risk scores were calculated using four different models: QRISK3, Framingham, PRIMROSE BMI, and PRIMROSE lipid. Risk estimates and classified risk categories were compared.

Results: QRISK3 identified 11 (39\%) as having $>10 \%$ risk of a CV event within 10 years, 4 (14\%) of whom exceeded 20\%. The Framingham model identified $4(14 \%)$ as exceeding $10 \%$, none of whom exceeded $20 \%$. PRIMROSE risk calculators identified no participants as having $>10 \%$ risk of a CV event within 10 years. Pairwise concordance correlation coefficients between types of model ranged 0.22-0.77. Mean ( $\pm S D$ ) age was $40( \pm 10)$ years but QRISK3's mean "Heart age" was $58( \pm 14)$ years.

Conclusion: Risk calculators generate differing predicted CVD risk scores for patients with schizophrenia. Using one risk calculator might yield different recommended monitoring and treatment plans compared to another. Clinicians should therefore take into account other patient-related factors, such as patients' preferences and other underlying physical conditions when making treatment decisions.

Keywords: schizophrenia, cardiovascular risk, risk calculator, cardiovascular disease, risk score 


\section{INTRODUCTION}

Globally, people diagnosed with schizophrenia have a mortality rate 2-3 times that of the general population (1) and their life expectancy is reduced by 10 to 30 years (1-3). As in the general population, cardiovascular disease (CVD) is the most common cause of death among these individuals (4-6). A meta-analysis of over 3 million patients with severe mental illness (SMI) and over 113 million controls from 92 studies with a cross-sectional or retrospective/prospective longitudinal design showed that people with schizophrenia are at more than double the risk of dying from CVD and are at 59\% greater risk of developing coronary heart disease (CHD) compared to the remainder of the population (7).

CVD risk calculators are used to estimate an individual's absolute risk of having a heart attack or stroke within a specified amount of time, such as 5 or 10 years. These calculators have been developed in large population studies and their validity and reproducibility assessed using population-level statistics that measure calibration and discrimination (8-11). CVD risk prediction scores are used in clinical practice with the general population to guide whether early intervention could be beneficial, such as prescribing medication to lower blood pressure and cholesterol (12). Moreover, in the United Kingdom (UK), the National Institute for Health and Care Excellence (NICE), which issues national clinical guidelines in the UK to improve health and social care (13) recommend routine monitoring of cardiovascular risk in people with schizophrenia (14).

Risk prediction scores can also be used as surrogate endpoints for intervention studies; that is, an outcome in a clinical trial would be change in CVD risk score after a certain period of time (15). In the schizophrenia population, risk prediction scores have been used as surrogate endpoints in intervention studies, for example the Clinical Antipsychotic Trials of Intervention Effectiveness (CATIE) trial included 1,125 people with schizophrenia and compared change in predicted 10-year CHD risk using the Framingham risk score (16) during antipsychotic treatment.

There are currently more than 360 CVD risk calculators available (17). A previously published review reported that 25 different calculators allocated the same person to a different risk category $33 \%$ of the time (18). Given the differences between risk calculators when applied in the general population, it would be useful to know whether or not consistency is similarly poor when the calculators are applied specifically to people with schizophrenia. Therefore, the aim of this study was to compare the 10 -year absolute CVD risk score in a sample of 30 people with schizophrenia using four different risk calculators: QRISK3 (9), Framingham (11), The PRedIction, and Management of cardiovascular Risk in peOple with SEvere mental illnesses (PRIMROSE) body mass index (BMI) and PRIMROSE lipid (10). Whilst there are a large number of calculators to select from, we decided to focus on risk calculators that include risk factors applicable to people with schizophrenia, such as an SMI diagnosis and antipsychotic use. Such risk factors may confer additional risk for CVD, independent of traditional predictors $(19,20)$. Furthermore, we chose to assess Framingham due to it being a calculator still commonly used worldwide, including
TABLE 1 | Comparison of risk factors included in four cardiovascular risk calculators.

\begin{tabular}{|c|c|c|c|c|}
\hline \multirow[t]{2}{*}{ Variables } & \multicolumn{4}{|c|}{ Cardiovascular risk calculators } \\
\hline & Framingham & QRISK3 & $\begin{array}{l}\text { PRIMROSE } \\
\text { Lipid }\end{array}$ & $\begin{array}{c}\text { PRIMROSE } \\
\text { BMI }\end{array}$ \\
\hline Age & $\checkmark$ & $\checkmark$ & $\checkmark$ & $\checkmark$ \\
\hline Gender & $\checkmark$ & $\checkmark$ & $\checkmark$ & $\checkmark$ \\
\hline Ethnicity & $x$ & $\checkmark$ & $x$ & $x$ \\
\hline HDL cholesterol & $\checkmark$ & $\checkmark$ & $\checkmark$ & $x$ \\
\hline Total cholesterol & $\checkmark$ & $\checkmark$ & $\checkmark$ & $x$ \\
\hline Systolic blood pressure & $\checkmark$ & $\checkmark$ & $\checkmark$ & $\checkmark$ \\
\hline $\begin{array}{l}\text { SD of two systolic } \\
\text { blood pressure } \\
\text { readings }\end{array}$ & $x$ & $\checkmark$ & $x$ & $x$ \\
\hline Type 2 diabetes & $\checkmark$ & $\checkmark$ & $\checkmark$ & $\checkmark$ \\
\hline Type 1 diabetes & $x$ & $\checkmark$ & $x$ & $x$ \\
\hline Current smoker & $\checkmark$ & $\checkmark$ & $\checkmark$ & $\checkmark$ \\
\hline Ex-smoker & $x$ & $\checkmark$ & $\checkmark$ & $\checkmark$ \\
\hline $\begin{array}{l}\text { Light/moderate/heavy } \\
\text { smoker }\end{array}$ & $x$ & $\checkmark$ & $x$ & $x$ \\
\hline Hypertension treatment & $\checkmark$ & $\checkmark$ & $\checkmark$ & $\checkmark$ \\
\hline BMl & $x$ & $\checkmark$ & $x$ & $\checkmark$ \\
\hline $\begin{array}{l}\text { Townsend index of } \\
\text { deprivation }\end{array}$ & $x$ & $\checkmark$ & $\checkmark$ & $\checkmark$ \\
\hline Family history of CVD & $x$ & $\checkmark$ & $x$ & $x$ \\
\hline Chronic kidney disease & $x$ & $\checkmark$ & $x$ & $x$ \\
\hline Migraines & $x$ & $\checkmark$ & $x$ & $x$ \\
\hline Lupus (SLE) & $x$ & $\checkmark$ & $x$ & $x$ \\
\hline Rheumatoid arthritis & $x$ & $\checkmark$ & $x$ & $x$ \\
\hline Erectile dysfunction & $x$ & $\checkmark$ & $x$ & $x$ \\
\hline Atrial fibrillation & $x$ & $\checkmark$ & $x$ & $x$ \\
\hline $\begin{array}{l}\text { History of heavy } \\
\text { drinking }\end{array}$ & $x$ & $x$ & $\checkmark$ & $\checkmark$ \\
\hline SMI diagnosis & $x$ & $\checkmark$ & $\checkmark$ & $\checkmark$ \\
\hline $\begin{array}{l}\text { Prescription for atypical } \\
\text { antipsychotics }\end{array}$ & $x$ & $\checkmark$ & $\checkmark$ & $\checkmark$ \\
\hline $\begin{array}{l}\text { Prescription for typical } \\
\text { antipsychotics }\end{array}$ & $x$ & $x$ & $x$ & $\checkmark$ \\
\hline $\begin{array}{l}\text { Prescription for } \\
\text { antidepressants }\end{array}$ & $x$ & $x$ & $\checkmark$ & $\checkmark$ \\
\hline Oral steroids & $x$ & $\checkmark$ & $x$ & $x$ \\
\hline
\end{tabular}

in this patient group. Table 1 shows a comparison of risk factors measured in each model that we have selected: QRISK3, Framingham, PRIMROSE BMI, and PRIMROSE Lipid.

\section{METHODS}

\section{Sample}

Individuals were eligible to take part if they were aged 1865 and had a diagnosis of schizophrenia or related psychosis, according to the ICD-10 classification system (21). Individuals were excluded if they were non-English speaking, were unable to give their informed consent, or they had a history of CVD as specified by the CVD risk calculators used $(9,11)$, as well as NICE 
guidelines (22). These individuals are already considered at highrisk of CVD events, therefore generating a risk score does not add useful additional information (22). Participants were recruited from Greater Manchester Mental Health NHS Foundation Trust services in England. All were given an information sheet to read and provided their written informed consent. The study received ethical approval from the North West Research Ethics Committee (17/NW/0368). Thirty participants were included in the study. Seventeen participants resided in the community and 13 were inpatients on mental health or rehabilitation wards. Participants' histories of diagnosed CVD were established by reviewing their medical records for related diagnoses and for any prescribed medication associated with cardiometabolic conditions.

\section{CVD Risk Calculators}

\section{Framingham}

The Framingham risk scores (11) apply an algorithm that calculates the predicted CVD risk from risk factors such as diabetes, dyslipidemia, hypertension (23-25), smoking, and obesity $(26,27)$. This risk calculator is frequently used in the general population but has also been applied to population groups with SMI (28). The prevalence of these risk factors is considerably raised in people with schizophrenia $(4,29-31)$ and people with schizophrenia have been shown to have higher risk scores than the general population (32-34). However, people with SMI were excluded from the Framingham cohort. As such, risk factors of particular relevance to those with an SMI diagnosis, such as antipsychotic use are not included. Yet antipsychotic use can cause significant morbidity, including weight gain (35, 36) and diabetes (37), conditions that are associated with an increased risk of CVD.

When applying the Framingham risk calculator to patients in the United Kingdom (UK), NICE recommends using the modified version (38). The modified version entails multiplying the results of the US Framingham score by 1.4 for south Asian men in the UK. Patients are considered to be at high risk of a CVD event over the next 10 years if they score $20 \%$ or greater (11). Estimates of risk include several CVD outcomes, including coronary death, myocardial infarction, coronary insufficiency, angina pectoris, ischaemic stroke, haemorrhagic stroke, transient ischaemic attack, peripheral artery disease, and heart failure (39).

\section{PRIMROSE}

The PRIMROSE BMI and lipid models are 10-year predicted cardiovascular risk calculators specifically designed for people with SMI (10). They include risk factors relevant to people with SMI, such as prescription of antipsychotic medication, antidepressant medication, history of heavy alcohol consumption, area-level Townsend index of deprivation (in quintiles) (40) and diagnosis of an SMI. These models were validated using The Health Improvement Network (THIN) UK primary care database (10).

The PRIMROSE BMI risk calculator excludes lipid profile. Patients are considered to be at high risk of a CVD event over the next 10 years if they score $20 \%$ or greater (10). The PRIMROSE lipid model excludes BMI and, again, patients are considered to be at high risk of a CVD event over the next 10 years if they score $20 \%$ or greater (10). Outcomes for which risks are in predicted in both PRIMROSE risk calculators cover both fatal and non-fatal cardiovascular events including myocardial infarction, angina pectoris, coronary heart disease, major coronary surgery and revascularization, cerebrovascular accident, and transient ischaemic attack (10).

\section{QRISK3}

The QRISK2 risk calculator is recommended for use with the UK general population by NICE (41). NICE also recommends QRISK2 for use in those with medical conditions including SMI, whilst acknowledging it may underestimate risk in such groups (22). QRISK2 is about to be superseded by QRISK3, which includes both typical risk indicators and specific factors for SMI (i.e., an SMI diagnosis and antipsychotic use) in patients aged 25-84 years (9) and may enable more accurate assessment. The QRISK algorithms have been validated using UK primary care databases including the Clinical Practice Research Datalink (CPRD) (42) and THIN (43-45). As well as calculating the 10year risk of CVD, QRISK3 also estimates a "heart age." This is calculated by comparing the ideal age of healthy individuals who receive the same predicted CVD risk score and have the same sex and ethnicity (46). A heart age older than the current age suggests increased risk that is modifiable (46). It is important to emphasize that this is a relative measure and heart age has been found on average to be older than chronological age in every age strata (47). It may be a useful tool to encourage lifestyle modification rather than to inform medication recommendations (48).

Using the QRISK3, patients are considered to be at high risk of a CVD event over the next 10 years if they score $10 \%$ or greater (9). This threshold was set following health economics modeling for when to offer medical intervention, such as with statins prescription (38). Risks are estimated for the following CVD outcomes: transient ischaemic attack and related syndromes, angina pectoris, myocardial infarction, subsequent myocardial infarction, complications after myocardial infarction, other acute ischaemic heart disease, chronic ischaemic heart disease, cerebral infarction, and stroke not specified as hemorrhage or infarction (9).

\section{Anthropometric Measurements}

BMI was calculated as weight $/$ height $^{2}\left(\mathrm{~kg} / \mathrm{m}^{2}\right)$. Participants were classified according to the World Health Organization (WHO) criteria as underweight (BMI <18.5), normal (BMI 18.524.99), overweight (BMI 25-29.99) obese (BMI 30-39.99), or severe obesity $(\mathrm{BMI} \geq 40)$ (49). Medical records were reviewed for any diagnosed physical and mental health conditions, prescribed medication and to confirm self-reported demographic information.

\section{Statistical Analyses}

Data were analyzed using STATA (version 11; Statacorp, TX, USA). Descriptive statistics were reported as medians, means, standard deviations (SDs) and percentages. 10-year predicted cardiovascular risk scores were calculated using published algorithms (9-11). The relationship between each CVD risk 
calculator model was assessed using concordance correlation coefficients $\left(\mathrm{P}_{\mathrm{c}}\right)$. This correlation measures how far the bestfit line differs from the line $\mathrm{y}=\mathrm{x}$, by adjusting the $r$-value using a bias correction factor. $\mathrm{P}_{\mathrm{c}}$ therefore provides a measure of correlation and agreement. Bland-Altman plots were generated to plot the difference against mean between pairs of CVD risk calculators.

\section{RESULTS}

\section{Sociodemographic and Summary Data}

The study sample included 30 participants. Their mean age was $40.4 \pm 10.2$ years and $83 \%$ were male. Most of the participants were overweight, with $33 \%$ being either obese (BMI $\geq 30 \mathrm{~kg} / \mathrm{m}^{2}$ ) or severely obese $\left(\mathrm{BMI} \geq 40 \mathrm{~kg} / \mathrm{m}^{2}\right)$ and the mean BMI was in the overweight range (29.9 \pm 7.9 ; Table 2$)$. Atypical antipsychotics were prescribed to $83 \%$ of participants; typical antipsychotics were prescribed to $27 \%$ of participants. Both atypical and typical antipsychotics were prescribed to $10 \%$ of these participants.

\section{0-Year Predicted CVD Risk}

Participants' absolute 10-year risk of CVD was calculated using four different risk calculators: QRISK3, Framingham, PRIMROSE BMI, and PRIMROSE lipid. Two participants were excluded from the QRISK3 analysis due to their age being below 25 years. One participant was excluded from the Framingham and PRIMROSE lipid analyses due to an inability to draw blood and obtain their lipid profile. QRISK3 identified 11 participants (39\%) who were classified into the high-risk category of having a CVD event within 10 years (range $0.4-38.5 \%$ ), based on a $10 \%$ threshold for high-risk. No participants were classified into the high risk category for the PRIMROSE lipid (range 0.1-8.5\%), PRIMROSE BMI (range 0.2-7.4\%), or Framingham (range 0.1$15.6 \%$ ) risk calculators, based on a $20 \%$ threshold for high-risk. However, if a $10 \%$ threshold is imposed across all four calculators, $39 \%$ of patients are categorized as high-risk with QRISK3, 14\% with Framingham and none with PRIMROSE risk calculators. If a $20 \%$ threshold is imposed across all four calculators, $14 \%$ are categorized as high risk by QRISK3 and none with other the other risk calculators (Table 3 ).

\section{Heart Age}

Frequency distributions of age and heart age calculated using QRISK3 can be seen in Figures 1, 2. The mean heart age was 58.4 \pm 13.5 . The mean difference between age and calculated heart age was found to be over 16 years with one individual scoring a heart age 40 years above their actual age (Figure 3 ).

\section{Agreement Between 10-Year Predicted CVD Risk Models}

Pairwise concordance correlation coefficients were highest between the two PRIMROSE measures but the QRISK3 and PRIMROSE metrics had notably poor correlations, not even reaching the acceptable range at their upper CIs and close to zero at the lower CIs (Table 4; Figure 4).
TABLE 2 | Distribution of sociodemographic and clinical factors in the sample of patients diagnosed with schizophrenia.

\begin{tabular}{lcccc}
\hline & $\boldsymbol{N}$ & $\%$ & Mean \pm SD & Median \\
\hline GENDER & 25 & 83 & & \\
Male & 5 & 17 & $40.4 \pm 10.2$ & 40 \\
Female & & & \\
Age & 9 & 30 & \\
18-34 & 21 & 70 & \\
35-64 & & & \\
ETHNICITY & 19 & 63 & \\
White British & 4 & 13 & \\
Black British/African & 2 & 7 & \\
Black British/Caribbean & 5 & 17 & \\
Other ethnic groups & & & \\
SMOKING & 22 & 73 \\
Current smoker & 5 & 17 \\
EX-smoker & 3 & 10 \\
Never smoked & 4 & 13 \\
DIAGNOSIS OF TYPE 2 DIABETES & \\
Yes & 26 & 87 \\
No & &
\end{tabular}

PRESCRIBED ANTI-DEPRESSANT MEDICATION

$\begin{array}{lll}\text { Yes } & 12 & 40 \\ \text { No } & 18 & 60\end{array}$

$\begin{array}{lcc}\text { PRESCRIBED STATINS } & & \\ \text { Yes } & 7 & 23 \\ \text { No } & 23 & 77\end{array}$

PRESCRIBED HYPERTENSIVE TREATMENT

Yes

No

Systolic blood

$7 \quad 23$

pressure

$<120 \mathrm{mmHg}$

23

$\geq 120-139 \mathrm{mmHg}$

11- 37

$\geq 140 \mathrm{mmHg}$

BMI

Underweight (<18.5)

Normal (18.5-24.99)

Overweight (25-29.99)

Obese (30-39.99)

Severe obesity $(\geq 40)$

77

Systolic Blood Pressure.

\section{DISCUSSION}

We applied four risk calculators to determine the predicted CVD risk for 30 patients with schizophrenia over the next 10 years. Mean QRISK3 calculated risk estimates were approximately 4 times higher than the PRIMROSE lipid calculated risk estimates, and roughly 3 times higher than PRIMROSE BMI. Moreover, agreement between calculators was poorest between QRISK3 and the PRIMROSE calculators, despite these calculators taking into account diagnosis of SMI and use of antipsychotic medication within their algorithms. These risk factors are known to have 
TABLE 3 | Ten-year predicted CVD risk scores according to 4 different risk calculators.

\begin{tabular}{|c|c|c|c|c|c|c|c|}
\hline & \multicolumn{2}{|c|}{$<10 \%$} & \multicolumn{2}{|c|}{$10-19 \%$} & \multicolumn{2}{|c|}{$20 \%$ or more } & \multirow[t]{2}{*}{ Mean* $^{*}$ SD } \\
\hline & $N$ & $\%$ & $N$ & $\%$ & $N$ & $\%$ & \\
\hline QRISK3 & 17 & 61 & 7 & 25 & 4 & 14 & $9.3 \pm 8.8$ \\
\hline Framingham & 25 & 86 & 4 & 14 & 0 & 0 & $4.1 \pm 4.1$ \\
\hline PRIMROSE Lipid & 29 & 100 & 0 & 0 & 0 & 0 & $2.0 \pm 2.0$ \\
\hline PRIMROSE BMI & 30 & 100 & 0 & 0 & 0 & 0 & $2.9 \pm 2.1$ \\
\hline
\end{tabular}

*Mean \% of 10-year predicted CVD risk.

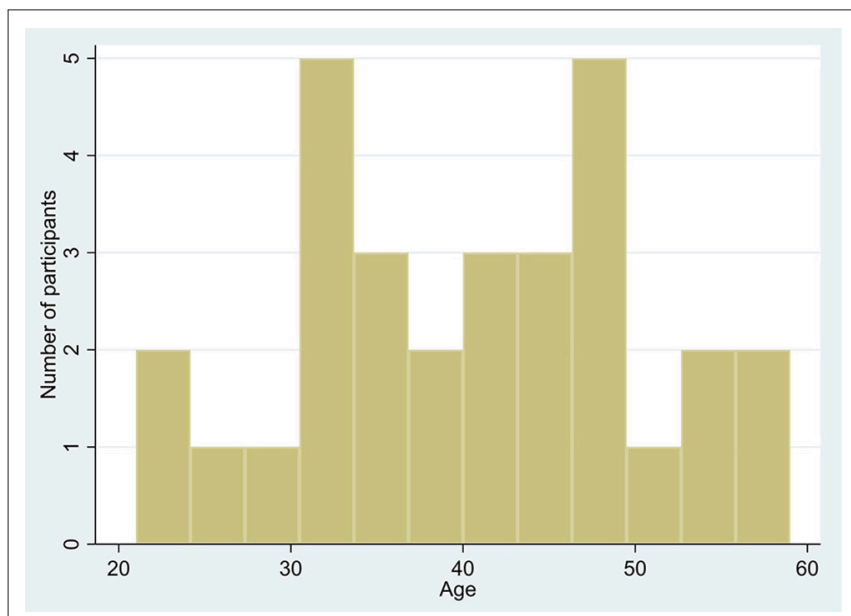

FIGURE 1 | Distribution of age.

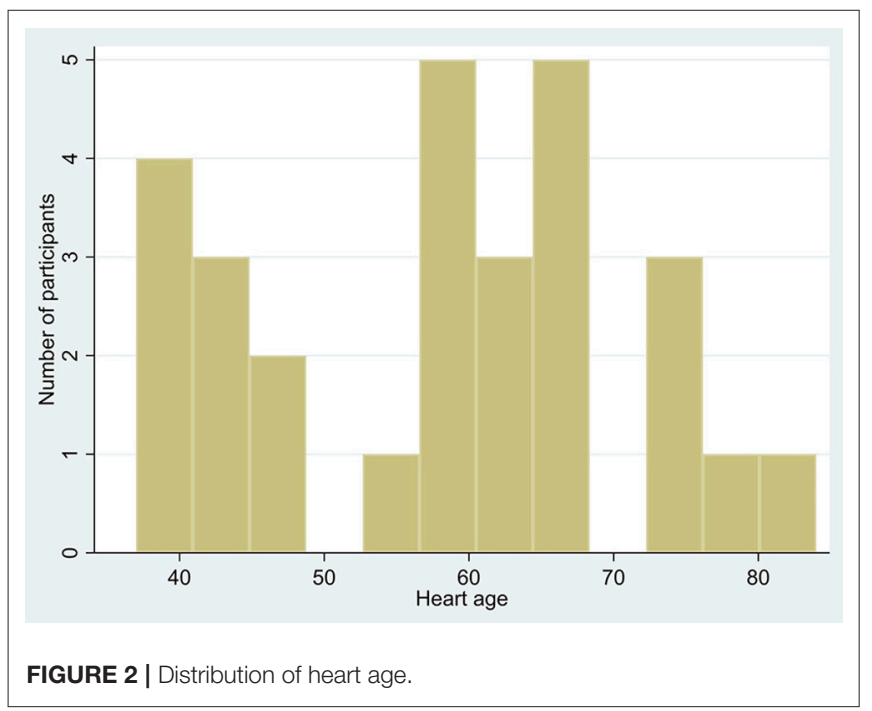

a complex effect on cardiovascular risk (9) and the lack of agreement highlights the variability in the weighting of risk factors between these models, which impacts the relative risk. Agreement between Framingham and the three other risk calculators was more acceptable but not high. People with SMI were excluded from the Framingham heart study cohort and

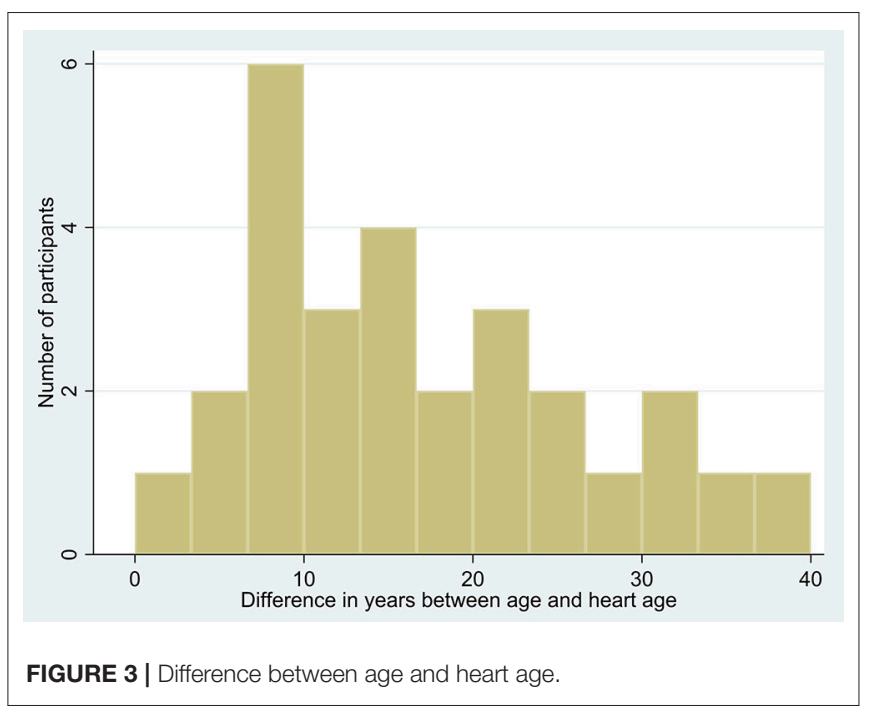

previous research comparing cardiovascular risk calculators in the general population has recommended selecting calculators that have been developed from a population similar to the patient (50).

People with schizophrenia and related conditions are recommended to attend for regular physical health assessments, including checking for cardiometabolic indicators specifically so that clinicians may offer any required interventions (51). For the purposes of CVD prevention, it is therefore important for clinicians to be able to identify individuals at highest risk of developing CVD. There is currently a lack of reliable evidence indicating the superiority of one CVD risk calculator over another, particularly in relation to persons with SMI. Our data suggest that there are important differences between calculators.

The threshold for classifying a patient as high-risk of having a CVD event over the next 10 years differed between the models. Thirty nine percent of participants were classified as high-risk using QRISK3, but all were classified as low-risk using the other calculators. Framingham and the PRIMROSE risk calculators both set the threshold as $20 \%$ or greater, while QRISK3 sets the threshold as $10 \%$ or greater. NICE guidelines recommend using a $10 \%$ threshold for initiating preventative therapy with statins (52). It is however not clear whether this is the optimal threshold for modifying risk in people with schizophrenia. For clinicians it is therefore not clear when to initiate preventative therapy or which risk calculator to use with patients with SMI. NICE emphasizes that faced with the challenge of applying population-based measures to individuals, clinicians should exercise their judgement and include patients' preferences when making clinical decisions in relation to CVD risk scores (53). There may also be other patient-related factors that should be considered, such as socioeconomic status or other underlying medical conditions (53).

The risk factors included in the algorithms for CVD risk calculators typically include age, gender, medical diagnoses, prescription to medications, BMI, blood pressure, and lipid profile. With the exception of smoking in all risk calculators, 
TABLE 4 | Agreement among 10-year predicted CVD risk models (\%).

\begin{tabular}{|c|c|c|c|c|}
\hline & \multicolumn{2}{|c|}{ Difference } & \multirow[t]{2}{*}{$95 \%$ Limits of agreement } & \multirow[t]{2}{*}{$P_{c}(95 \% \mathrm{Cl})$} \\
\hline & Mean & SD & & \\
\hline QRISK3 vs. Framingham & 5.0 & 5.4 & -5.7 to 15.7 & 0.549 (0.41 to 0.69$)$ \\
\hline QRISK3 vs. PRIMROSE Lipid & 7.2 & 7.3 & -7.1 to 21.6 & 0.224 (0.12 to 0.32$)$ \\
\hline QRISK3 vs. PRIMROSE BMI & 6.2 & 7.4 & -8.2 to 20.6 & 0.226 (0.12 to 0.33$)$ \\
\hline Framingham vs. PRIMROSE Lipid & 2.1 & 2.6 & -3.0 to 7.3 & 0.543 (0.38 to 0.70$)$ \\
\hline Framingham vs. PRIMROSE BMI & 1.2 & 2.8 & -4.3 to 6.7 & 0.581 (0.41 to 0.75$)$ \\
\hline PRIMROSE Lipid vs. PRIMROSE BMI & -0.9 & 1.2 & -3.2 to 1.4 & 0.767 (0.63 to 0.91$)$ \\
\hline
\end{tabular}

$P_{C}$, Concordance correlation coefficient; $\mathrm{Cl}$, confidence intervals.
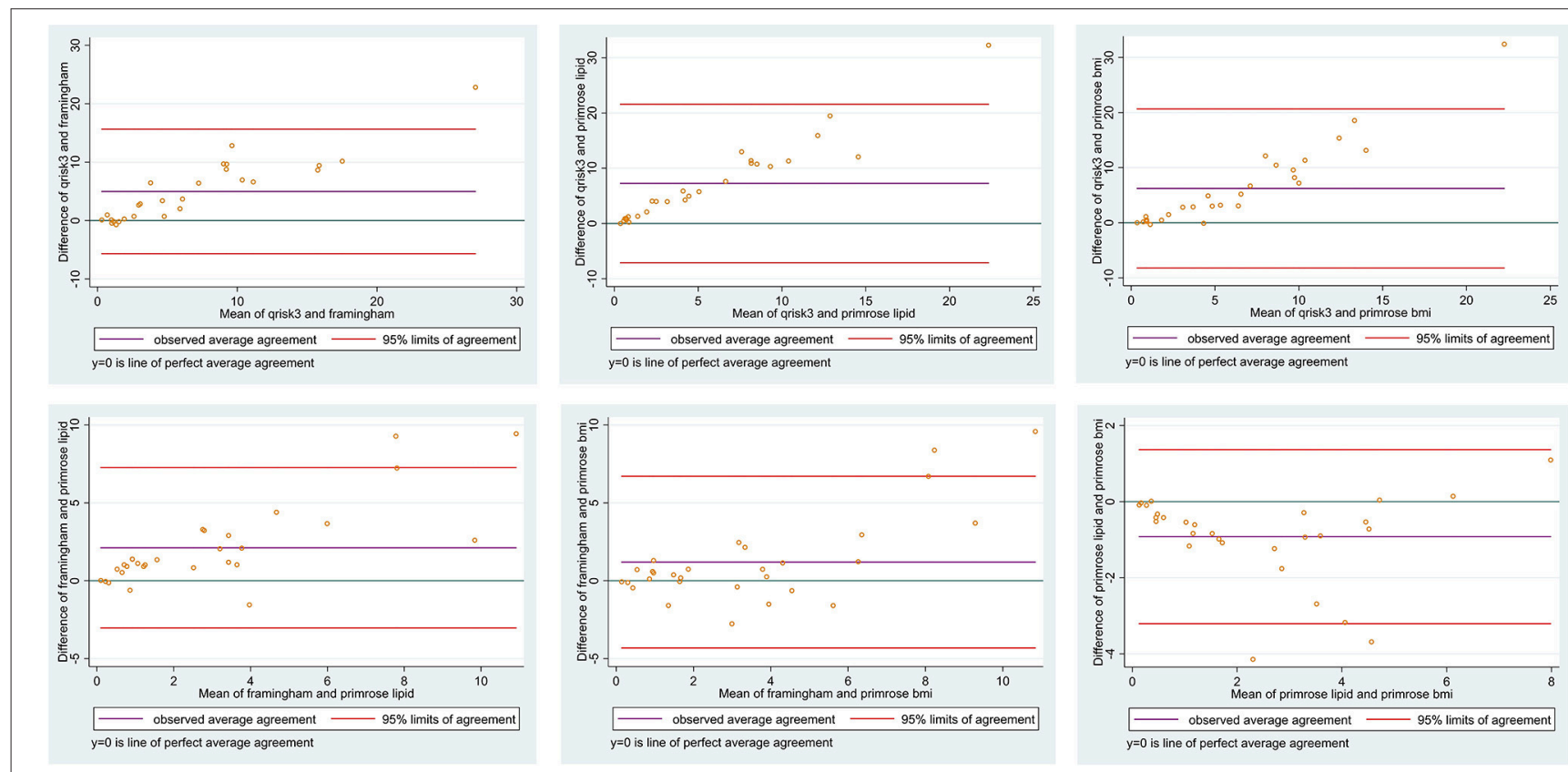

FIGURE 4 | Difference against mean between 10-year predicted CVD risk calculators.

and history of heavy drinking within PRIMROSE risk calculators (10), lifestyle screening is not included. Lifestyle screening contributes little to CVD risk calculator algorithms, partly because resource limitations mean lifestyle factors are not routinely recorded within primary care databases from which risk models derive. However, many lifestyle factors have been found to increase the risk of CVD both in the general population and SMI groups. Meta-analyses show that sedentary behavior in the general population is associated with increased risks of diabetes, CVD and cardiovascular and all-cause mortality (54); and that those with schizophrenia group engage in high levels of sedentary behavior (55). Furthermore, sleep disorders are reported in $30-80 \%$ of people with schizophrenia $(56,57)$. They take longer to fall asleep, sleep longer, take daytime naps and have severely fragmented sleep compared to healthy controls (58). There is emerging evidence that disrupting sleep can cause health problems, such as CVD (59). It may be that sleep quality needs to be routinely enquired about and its role in CVD risk calculators investigated
Comparing models, it is notable that the low PRIMROSE and Framingham risk scores seem at odds with clinical impressions of participants and with studies of life expectancy, CVD and CVD risk factor prevalence in people with schizophrenia. People with schizophrenia have 2.5 times the risk of dying compared to the general population (1), and a mean age of death from CVD in schizophrenia patients was found to be 51 years (60). Moreover, general population life expectancy in the UK is lowest in northern urban England, including Manchester (61), with healthy male life expectancy at birth in Greater Manchester in the 50s (54). This implies that a substantial proportion of this sample should be in a high-risk category. QRISK3 estimated our participant heart ages to be a mean of 16 years older than chronological age. Whilst "heart age" may not be an accurate enough tool to inform medical decision-making (48), an age adjustment of this size may be similar to the substantial reduction in life expectancy in this group.

Our study was limited by its small sample size, which makes it difficult to draw generalisable conclusions and we 
therefore recommend repeating this study on a considerably large scale. The sample was recruited from Greater Manchester in England by volunteers. This is an area where health and life expectancy is unusually poor in the general population (54), so this sample may well not be representative. However, this may have enabled us to detect higher rates of predicted CVD risk in this group. A longitudinal study of a representative cohort of sufficient size to accurately estimate agreement among CVD risk calculators is indicated. This study underlines the importance of such work in that, even in a small study, differences were observed between algorithms in their risk predictions.

\section{CONCLUSIONS}

Existing CVD risk calculators have low agreement with each other in our sample of people diagnosed with schizophrenia. This makes it challenging to draw conclusions about which tool is most suitable for clinicians to use with this population group, and how to treat patients who fall in different categories when using one calculator rather than another. It is recommended that clinicians consider multiple patient-related factors in addition to predicted CVD risk score when recommending treatment. Furthermore, participants in our study had a calculated heart age that was much older than their actual ages. Of interest would be whether adjusting the age of patients with schizophrenia more accurately predicts CVD events. Further research is needed with larger numbers and with longitudinal follow-up to assess actual CVD events to understand this further. Also of interest

\section{REFERENCES}

1. Saha S, Chant D, McGrath J. A systematic review of mortality in schizophrenia: is the differential mortality gap worsening over time? Arch Gen Psychiatry (2007) 64:1123-31. doi: 10.1001/archpsyc.64.10.1123

2. Wahlbeck K, Westman J, Nordentoft M, Gissler M, Laursen TM. Outcomes of nordic mental health systems: life expectancy of patients with mental disorders. Br J Psychiatry (2011) 199:453-8. doi: 10.1192/bjp.bp.110.085100

3. De Hert M, Cohen D, Bobes J, Cetkovich-Bakmas M, Leucht S, Ndetei $\mathrm{DM}$, et al. Physical illness in patients with severe mental disorders. II. barriers to care, monitoring and treatment guidelines, plus recommendations at the system and individual level. World Psychiatry (2011) 10:138. doi: 10.1002/j.2051-5545.2011.tb00014.x

4. Hennekens CH, Hennekens AR, Hollar D, Casey DE. Schizophrenia and increased risks of cardiovascular disease. Am Heart J. (2005) 150:1115-21. doi: 10.1016/j.ahj.2005.02.007

5. Brown S. Excess mortality of schizophrenia. a meta-analysis. Br J Psychiatry (1997) 171:502-8. doi: 10.1192/bjp.171.6.502

6. Westman J, Eriksson SV, Gissler M, Hallgren J, Prieto ML, Bobo WV, et al. Increased cardiovascular mortality in people with schizophrenia: a 24-year national register study. Epidemiol Psychiatr Sci. (2017) 5:1-9. doi: $10.1017 /$ S2045796017000166

7. Correll CU, Solmi M, Veronese N, Bortolato B, Rosson S, Santonastaso P, et al. Prevalence, incidence and mortality from cardiovascular disease in patients with pooled and specific severe mental illness: a large-scale metaanalysis of 3,211,768 patients and 113,383,368 controls. World Psychiatry (2017) 16:163-80. doi: 10.1002/wps.20420

8. Hippisley-Cox J, Coupland C, Vinogradova Y, Robson J, Minhas R, Sheikh A, et al. Predicting cardiovascular risk in England and Wales: would be the use of large datasets to examine the question of CVD risk in schizophrenia. Such studies should also investigate if any of the factors known to increase risk of CVD in the general population that are also common in schizophrenia, such as physical inactivity (55-57), high rates of sedentary behavior (58), and sleep disturbance $(59,62)$ impact on CVD risk, independent of the risk factors already included in existing CVD risk calculators.

\section{AUTHOR CONTRIBUTIONS}

$\mathrm{AB}, \mathrm{AY}$, and $\mathrm{RD}$ contributed conception and design of the study. $\mathrm{AB}$ collected the data. $\mathrm{AB}$ and $\mathrm{RD}$ performed the statistical analysis. $\mathrm{AB}$ and $\mathrm{AY}$ wrote the first draft of the manuscript. $\mathrm{AB}, \mathrm{AY}$, and $\mathrm{RD}$ wrote sections of the manuscript. All authors contributed to manuscript revision, read and approved the submitted version.

\section{FUNDING}

This piece of research was funded by the Medical Research Council and University of Manchester as part of AB's MRC Doctoral Training Scholarship.

\section{ACKNOWLEDGMENTS}

Dr. Stephen Hippisley-Cox is acknowledged for providing risk prediction algorithm support. Thanks to ClinRisk Ltd for providing QRISK3 risk prediction support. prospective derivation and validation of QRISK2. BMJ (2008) 336:a332. doi: $10.1136 / \mathrm{bmj} .39609 .449676 .25$

9. Hippisley-Cox J, Coupland C, Brindle P. Development and validation of QRISK3 risk prediction algorithms to estimate future risk of cardiovascular disease: prospective cohort study. BMJ (2017) 357: j2099. doi: $10.1136 / \mathrm{bmj} . j 2099$

10. Osborn DP, Hardoon S, Omar RZ, Holt RIG, King M, Larsen J, et al. The PRIMROSE cardiovascular risk prediction models for people with severe mental illness: results from the PRIMROSE Research Programme: prediction and management of cardiovascular risk in people with severe mental illnesses. JAMA Psychiatry (2015) 72:143-51. doi: 10.1001/jamapsychiatry. 2014.2133

11. D'Agostino RS, Vasan RS, Pencina MJ. General cardiovascular risk profile for use in primary care: the Framingham Heart Study. Circulation (2008) 117:743-53. doi: 10.1161/CIRCULATIONAHA.107. 699579

12. Jackson R, Lawes CMM, Bennett DA, Milne RJ, Rodgers A. Treatment with drugs to lower blood pressure and blood cholesterol based on an individual's absolute cardiovascular risk. Lancet (2005) 365:434-41. doi: 10.1016/S0140-6736(05)70240-3

13. National Institute for Health and Care Excellence (NICE). About 2018. Available online: https://www.nice.org.uk/about (Accessed October 2, 2018).

14. National Institute for Health and Care Excellence (NICE). Psychosis and Schizophrenia in Adults: Prevention and Management 2014 Available online at: https://www.nice.org.uk/guidance/cg178/chapter/1-Recommendations (Accessed November 5, 2018)

15. Maruthur NM, Wang NY, Appel LJ. Lifestyle interventions reduce coronary heart disease risk: results from the PREMIER trial. Circulation (2009) 119:2026-31. doi: 10.1161/CIRCULATIONAHA.108.809491 
16. Daumit GL, Goff DC, Meyer JM, Davis VG, Nasrallah HA, McEvoy JP, et al. Antipsychotic effects on estimated 10-year coronary heart disease risk in the CATIE schizophrenia study. Schizophr Res. (2008) 105:175-87. doi: 10.1016/j.schres.2008.07.006

17. Damen JAAG, Hooft L, Schuit E, Debray TPA, Collins GS, Tzoulaki I, et al. Prediction models for cardiovascular disease risk in the general population: systematic review. BMJ (2016) 353:i2416. doi: 10.1136/bmj.i2416

18. Allan GM, Nouri F, Korownyk C, Kolber MR, Vandermeer B, McCormack J. Agreement among cardiovascular disease risk calculators. Circulation (2013) 127:1948-56. doi: 10.1161/CIRCULATIONAHA.112.000412

19. De Hert M, Detraux J, van Winkel R, Yu W, Correll CU. Metabolic and cardiovascular adverse effects associated with antipsychotic drugs. Nat Rev Endocrinol. (2011) 8:114. doi: 10.1038/nrendo.2011.156

20. Ösby U, Westman J, Hällgren J, Gissler M. Mortality trends in cardiovascular causes in schizophrenia, bipolar and unipolar mood disorder in Sweden 1987-2010. Eur J Public Health (2016) 26:867-71. doi: 10.1093/eurpub/ckv245

21. World Health Organization. The ICD-10 Classification of Mental and Behavioural Disorders. Diagnostic Criteria for Research. Geneva: World Health Organization (1993).

22. National Institute for Health and Care Excellence (NICE). Cardiovascular Risk Assessment and Lipid Modification 2015. Available online at: https:// www.nice.org.uk/guidance/qs100/resources/cardiovascular-risk-assessmentand-lipid-modification-pdf- 75545230925509 (Accessed October 30, 2018).

23. Kannel WB, Gordon T, Schwartz MJ. Systolic versus diastolic blood pressure and risk of coronary heart disease: the Framingham Study. Am J Cardiol. (1971) 27:335-46. doi: 10.1016/0002-9149(71)90428-0

24. Castelli WP, Garrison RJ, Wilson PWF, Abbott RD, Kalousdian S, Kannel WB. Incidence of coronary heart disease and lipoprotein cholesterol levels the Framingham Study. JAMA (1986) 256:2835-8. doi: 10.1001/jama.1986.03380200073024

25. Kannel WB, McGee DL. Diabetes and cardiovascular disease. JAMA (1979) 241:2035-8. doi: 10.1001/jama.1979.03290450033020

26. Doyle JT, Dawber TR, Kannel WB, Heslin AS, Kahn HA. Cigarette smoking and coronary heart disease: combined experience of the Albany and Framingham studies. $N$ Eng J Med. (1962) 26:796-801. doi: 10.1056/NEJM196204192661602

27. Hubert HB, Feinleib M, McNamara PM, Castelli WP, Hubert MF, McNamara $\mathrm{PM}$, et al. Obesity as an independent risk factor for cardiovascular disease: a 26-year follow-up of participants in the Framingham Heart Study. Circulation (1983) 67:968-77. doi: 10.1161/01.CIR.67.5.968

28. Foguet-Boreu Q, Fernandez-San-Martin MI, Flores-Mateo G, Zabaletadel-Olmo E, Garcia-Morzon LA, Perez-Pinar Lopez M, et al. Cardiovascular risk assessment in patients with a severe mental illness: a systematic review and meta-analysis. BMC Psychiatry (2016) 16:141. doi: 10.1186/s12888-016-0833-6

29. Kelly DL, McMahon HJ, Wehring HJ, Liu F, Mackowick KM, Boggs DL, et al. Cigarette smoking and mortality risk in people with schizophrenia. Schizophr Bull. (2011) 37:832-8. doi: 10.1093/schbul/sbp152

30. Chuang HT, Mansell C, Patten SB. Lifestyle characteristics of psychiatric outpatients. Canad J Psychiatry (2008) 53:260-6. doi: $10.1177 / 070674370805300407$

31. Liao CH, Chang CS, Wei WC, Chang SN, Liao CC, Lane HY, et al. Schizophrenia patients at higher risk of diabetes, hypertension and hyperlipidemia: a population-based study. Schizophr Res. (2011) 126:110-6. doi: 10.1016/j.schres.2010.12.007

32. McCreadie RG. Diet, smoking and cardiovascular risk in people with schizophrenia. Br J Psychiatry (2003) 183:534-9. doi: 10.1192/bjp.183.6.534

33. Ratliff JC, Palmese LB, Reutenauer E, Srihari V, Tek C. Obese schizophrenia spectrum patients have significantly higher 10-year general cardiovascular risk and vascular ages than obese individuals without severe mental illness. Psychosomatics (2013) 54:67-73. doi: 10.1016/j.psym.2012.03.001

34. Tay Y, Nurjono M, Lee J. Increased Framingham 10-year CVD risk in Chinese patients with schizophrenia. Schizophr Res. (2013) 147:187-92. doi: 10.1016/j.schres.2013.03.023

35. Bak M, Fransen A, Janssen J, van Os J, Drukker M. Almost All Antipsychotics result in weight gain: a meta-analysis. PLoS ONE (2014) 9:e94112. doi: 10.1371/journal.pone.0094112
36. Allison D, Mentore J, Heo M, Chandler L, Cappelleri J, Infante M, et al. Antipsychotic-induced weight gain: a comprehensive research synthesis. Am J Psychiatry (1999) 156:1686-96.

37. Vancampfort D, Correll CU, Galling B, Probst M, De Hert M, Ward PB, et al. Diabetes mellitus in people with schizophrenia, bipolar disorder and major depressive disorder: a systematic review and large scale meta-analysis. World Psychiatry (2016) 15:166-74. doi: 10.1002/wps.20309

38. National Collaborating Centre for Primary Care (UK). Lipid Modification: Cardiovascular Risk Assessment and the Modification of Blood Lipids for the Primary and Secondary Prevention of Cardiovascular Disease. London: Royal College of General Practitioners (UK) (2008) Available online at: https://www.ncbi.nlm.nih.gov/books/NBK55501/?report=classic. [Accessed June 14th 2018].

39. Cupples LA, D'Agostino RB. Section 34: some risk factors related to the annual incidence of cardiovascular disease and death in pooled repeated biennial measurements. In: Kannel WB, Wolf PA, Garrison RJ, editors. Framingham Heart Study: 30 Year Follow-Up. Bethesda, MD: Department of Health and Human Services (1987).

40. Townsend P, Phillimore P, Beattie A. Health and Deprivation: Inequality and the North. London: Routledge (1988).

41. National Institute for Health and Care Excellence (NICE). Surveillance Report 2018 - Cardiovascular Disease: Risk Assessment and Reduction, Including Lipid Modification (2014) NICE guideline CG181: NICE. (2018). Available onlione at: https://www.nice.org.uk/guidance/cg181/resources/ surveillance-report-2018-cardiovascular-disease-risk-assessment-andreduction-including-lipid-modification-2014-nice-guideline-cg181-pdf6123288665797 (Accessed 25th September 2018).

42. Hippisley-Cox J, Coupland C, Brindle P. The performance of seven QPrediction risk scores in an independent external sample of patients from general practice: a validation study. BMJ Open. (2014) 4:5809. doi: 10.1136/bmjopen-2014-005809

43. Collins GS, Altman DG. Predicting the 10 year risk of cardiovascular disease in the United Kingdom: independent and external validation of an updated version of QRISK2. BMJ (2012) 2012:344. doi: 10.1136/bmj.e4181

44. Riley RD, Ensor J, Snell KIE, Debray TPA, Altman DG, Moons KGM, et al. External validation of clinical prediction models using big datasets from e-health records or IPD meta-analysis: opportunities and challenges. BMJ (2016) 2016:353. doi: 10.1136/bmj.i3140

45. Collins GS, Altman DG. An independent and external validation of QRISK2 cardiovascular disease risk score: a prospective open cohort study. BMJ (2010) 2010:340. doi: 10.1136/bmj.c2442

46. Wells S, Kerr A, Eadie S, Wiltshire C, Jackson R. 'Your Heart Forecast': a new approach for describing and communicating cardiovascular risk? Heart (2010) 96:708. doi: 10.1136/hrt.2009.191320

47. Yang Q, Zhong Y, Ritchey M, Cobain M, Gillespie C, Merritt R, et al. Vital Signs: Predicted Heart Age and Racial Disparities in Heart Age Among U.S. Adults at the State Level. MMWR Morb Mortal Wkly Rep [Internet]. (2015). Available online at: http://europepmc.org/abstract/MED/26335037

48. Bonner C, Bell K, Jansen J, Glasziou P, Irwig L, Doust J, et al. Should heart age calculators be used alongside absolute cardiovascular disease risk assessment? BMC Cardiovasc Disord. (2018) 18:19. doi: 10.1186/s12872-018-0760-1

49. World Health Organization. Physical Status: The Use and Interpretation of Anthropometry. Report of a WHO Expert Committee. WHO Technical Report Series 854. Geneva: World Health Organization (1995).

50. Allan GM, Garrison S, McCormack J. Comparison of cardiovascular disease risk calculators. Curr Opin Lipidol. (2014) 25:254-65. doi: 10.1097/MOL.0000000000000095

51. National Institute for Health and Care Excellence (NICE). NICE Impact Cardiovascular Disease Prevention. London: National Insitute for Health and Care Excellence (2018). Available online at: https://www.nice.org.uk/media/ default/about/what-we-do/into-practice/measuring-uptake/nice-impactcardiovascular-disease- prevention.pdf. (Accessed September 24th 2018).

52. Majeed A. Statins for primary prevention of cardiovascular disease. BMJ (2014) 2014:348. doi: 10.1136/bmj.g3491

53. National Institute for Health and Care Excellence (NICE). Cardiovascular Disease: Risk Assessment and Reduction, Including Lipid Modification. (2014). Available online at: https://www.nice.org.uk/guidance/cg181/resources/ 
cardiovascular-disease-risk-assessment-and-reduction-including-lipidmodification-pdf-35109807660997 (Accessed October 5th 2018).

54. Office for National Statistics (ONS). Health State Life Expectancy by 2011 Census Wards, England and Wales: 2009 to 2013. (2018). Available online at: https://www.ons.gov.uk/peoplepopulationandcommunity/ healthandsocialcare/healthandlifeexpectancies/articles/ healthstatelifeexpectancyby2011 censuswardsenglandandwales/2009to2013 (Accessed 5th October 2018).

55. Gardner-Sood P, Lally J, Smith S. Cardiovascular risk factors and metabolic syndrome in people with established psychotic illnesses: baseline data from the IMPaCT randomized controlled trial. Psychol. Med. (2015) 45:2619-29. doi: 10.1017/S0033291715000562

56. Snethen GA, McCormick BP, Lysaker PH. Physical activity and psychiatric symptoms in adults with schizophrenia spectrum disorders. J Nerv Mental Dis. (2014) 202. doi: 10.1097/NMD.0000000000000216

57. Vancampfort D, Probst M, Knapen J, Carraro A, De Hert M. Associations between sedentary behaviour and metabolic parameters in patients with schizophrenia. Psychiatry Res. (2012) 200:73-8. doi: 10.1016/j.psychres.2012.03.046

58. Stubbs B, Williams J, Gaughran F, Craig T. How sedentary are people with psychosis? A systematic review and meta-analysis. Schizophr Res. (2016) 171:103-9. doi: 10.1016/j.schres.2016.01.034

59. Tandon R, Shipley JE, Taylor S. Electroencephalographic sleep abnormalities in schizophrenia. Relationship to positive/negative symptoms and prior neuroleptic treatment. Arch General Psychiatry (1992) 49:185-94. doi: 10.1001/archpsyc.1992.01820030017003
60. Sweeting J, Duflou J, Semsarian C. Postmortem analysis of cardiovascular deaths in schizophrenia: a 10-year review. Schizophr Res. (2013) 150:398-403. doi: 10.1016/j.schres.2013.08.029

61. Bennett JE, Li G, Foreman K, Best N, Kontis V, Pearson C, et al. The future of life expectancy and life expectancy inequalities in England and Wales: Bayesian spatiotemporal forecasting. Lancet (2015) 386:163-70. doi: 10.1016/S0140-6736(15)60296-3

62. Keshavan MS, Keshavan MS, Saisps PM. Sleep abnormalities in schizophrenia: pathophysiological significance. Psychol Med. (1993) 23:831-5. doi: $10.1017 /$ S0033291700026313

Conflict of Interest Statement: AB published a research paper with the editor in 2016: How much physical activity do people with schizophrenia engage in A systematic review, comparative meta-analysis and meta-regression.

The remaining authors declare that the research was conducted in the absence of any commercial or financial relationships that could be construed as a potential conflict of interest.

Copyright $\odot 2018$ Berry, Drake, Webb, Ashcroft, Carr and Yung. This is an openaccess article distributed under the terms of the Creative Commons Attribution License (CC BY). The use, distribution or reproduction in other forums is permitted, provided the original author(s) and the copyright owner(s) are credited and that the original publication in this journal is cited, in accordance with accepted academic practice. No use, distribution or reproduction is permitted which does not comply with these terms. 